\title{
Impact of Micro-Climate on Ventilation Availability and Indoor Thermal Comfort
}

\author{
Sushanth SJ, E.Rajasekar \\ Department of Architecture and Planning, \\ Indian Institute of Technology Roorkee, India
}

\begin{abstract}
In response to global climate change, there is a strong urge for regulating the thermal performance and associated energy use in buildings. Typically, building performance assessments are carried out considering the influence of macro- environmental characteristics. However, micro-environmental variables also modulate the convective and radiative thermodynamic exchanges significantly. This study aims to analyse the impact of location-specific urban developments on the ventilation availability and in turn the thermal and comfort performance. For this purpose, a residential building located in Thiruvananthapuram, India $(8.5 \mathrm{~N} ; 76.9 \mathrm{E})$, is considered. The city represents a warm humid climate. The residential building under consideration is predominantly operated in a free-running mode. Thermal performance and comfort assessment of the building were carried out using Energy Plus tool. The paper presents two different scenarios - (1) Assessment carried out using standard weather data of the city and (2) Assessment carried out using the micro-climate data. The micro-climate data for the building location are obtained from a detailed micro climate model developed using the Cradle-SC Stream simulation tool. The study compares the variations in ventilation availability and its resulting impact on building thermal performance and comfort.
\end{abstract}

\section{Introduction}

Buildings are one of the largest energy consumers in most countries. Energy demand for heating and cooling keeps growing day by day. Accurate energy assessments and predictions are prime objectives of energy modellers to ensure the risk on investments. Typically, building performance assessments are carried out considering the influence of macro-environmental characteristics. However, apart from these factors, micro-environmental variables significantly modulate the convective and radiative thermodynamic exchanges between the building and the surrounding environment.

Extensive review of literature details the impact of microclimatic variables on indoor thermal comfort and energy use (Geros, Santamouris, Tsangrasoulis, \& Guarracino, 1999; Pisello, Pignatta, Castaldo, \& Cotana, 2015; Santamouris et al., 2001; Vallati, De Lieto Vollaro, Golasi, Barchiesi, \& Caranese, 2015). Alterations in urban microclimate occurs mainly due to urban built morphology, surface characteristics and anthropogenic heat (Dimoudi, Kantzioura, Zoras, Pallas,
\& Kosmopoulos, 2013). In the case of residential buildings, most of the cooling load originates from solar heat gains through the building envelope. Reduction of solar exposure on building envelope along with strategies for maximum utilization of wind flows to ventilate internal spaces will help to evacuate unwanted heat from the building and provide thermal comfort to the occupants. These objectives should be given due consideration while deciding on building massing and spatial configurations.

The main differences between the urban and rural micro-climatic conditions that affect human comfort, result from differences in air temperatures and wind speeds. Knowledge of wind field characteristics, velocity and direction, as well as of the temperature distribution inside street canyons are of vital importance for the sizing of openings in order to achieve the necessary airflow for cooling and air quality purposes (Georgakis \& Santamouris, 2006). Driven by wind and buoyancy forces, natural ventilation has a great potential to offset energy consumption by mechanical ventilation systems (Aflaki, Mahyuddin, Al-Cheikh Mahmoud, \& Baharum, 2015; Etheridge, 2015; Geros et al., 1999; Hughes, Chaudhry, \& Ghani, 2011; Oropeza-Perez \& Ostergaard, 2014; Oropeza-Perez \& Østergaard, 2014; Simonson, 2005). Based on measurements in Singapore and Bangkok, increasing the air speed by $1 \mathrm{~m} / \mathrm{s}$ resulted in a cooling effect equivalent to lowering the temperature by more than $2^{\circ} \mathrm{C}$ (Givoni, 2009). The airflow within the urban canopy layer is a driving force for the indoor ventilation of urban buildings and transfer of heat in urban streets. Assessing the effects of urban geometry on the airflow is an important issue for urban planning and building design in order to plan a more comfortable and healthy city (Abd Razak, Hagishima, Ikegaya, \& Tanimoto, 2013). Natural ventilation of buildings occurs due to wind forces and temperature difference between the indoor and outdoor environments or in combination of both. Natural ventilation of buildings located in urban canyons is severely reduced due to the significant decrease in the wind velocity inside the canyons. Design of urban buildings to improve natural ventilation potential should consider the appropriate wind data and not routine meteorological observations collected in open fields (Santamouris et al., 2001).

In response, this study focuses on influence of urban morphology on ventilation availability and building thermal and comfort performance. For this purpose, a 
residential building located at Thiruvananthapuram, is considered. In urban areas the wind space is classified as urban boundary layer and urban canopy layer (Oke, 1976). This study tries to find the variations in canopy layer's wind velocity due to variations in urban morphology and its implications on the building comfort and thermal performance. The urban morphology is represented by $\mathrm{L} / \mathrm{H}$ ratio, $\mathrm{H} / \mathrm{W}$ ratio and wind incidence angle. The first section of the study highlights the impact of urban morphology on ventilation availability and subsequent section explains its impact on thermal and comfort performances.

\section{Objectives and Methodology}

The objective of the study is to find the impact of microclimate on ventilation availability and in turn building thermal and comfort performance. A representative residential building in a neighbourhood, which falls in LCZ-2 of Thiruvananthapuram, was chosen for the study. Micro-climate data of the neighbourhood are developed using the Cradle-SC Stream software tool. A parametric study using Response Surface Model is conducted to find the relative impact of urban morphological variables such as H/W ratio, $\mathrm{L} / \mathrm{H}$ ratio and Wind incidence angle on ventilation availability. Thermal performance and comfort assessment of the building are carried out using Energy Plus for two different scenarios (1) an assessment carried out using standard weather data of the city and

(2) an assessment carried out using the micro-climate data (Variations in ventilation Availability).

Comparative study of the thermal performance assessment is carried out to establish the impact of microclimate on ventilation availability and indoor thermal comfort performance. Fig. 2 outlines the methodology adopted for this study. The study deals with the variations in ventilation availability due to urban morphological variables such as $\mathrm{L} / \mathrm{H}$ ratio, $\mathrm{H} / \mathrm{W}$ ratio and wind incidence angle. Other causal parameters like Surface properties and Form of the building and the impact of urban

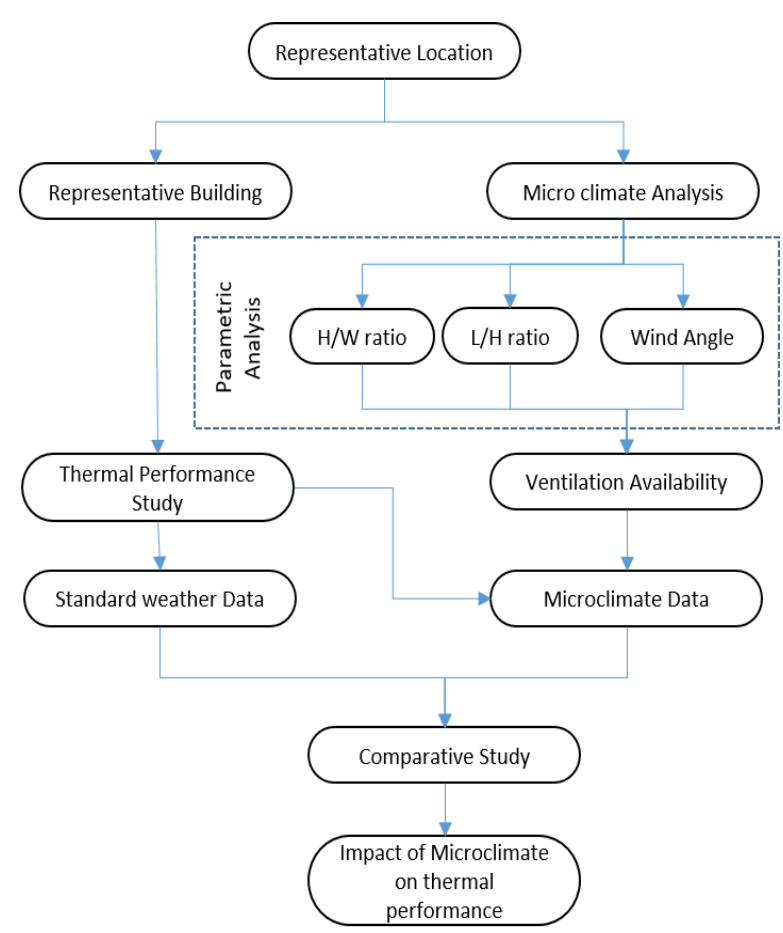

Figure 2:Methodology Adopted

morphological variables on other microclimatic variables like wind direction, solar irradiation and specular and diffuse reflections and temperature will require further study which shall be reported later.

\section{Location}

The chosen area of study is in Thiruvananthapuram, India $(8.5 \mathrm{~N} ; 76.9 \mathrm{E})$ which falls in warm humid climate zone. As per the weather data, the predominant wind direction is from SW- NE. It is observed that minimum, average and the maximum wind velocities experienced in the study were $0 \mathrm{~m} / \mathrm{s}, 4.5 \mathrm{~m} / \mathrm{s}$ and $14 \mathrm{~m} / \mathrm{s}$ respectively(Fig.1). The chosen neighbourhood is in LCZ-2. 'Local Climate Zone(LCZ), is a land classification system developed by Stewart and Oke (Stewart \& Oke, 2012), in which regions
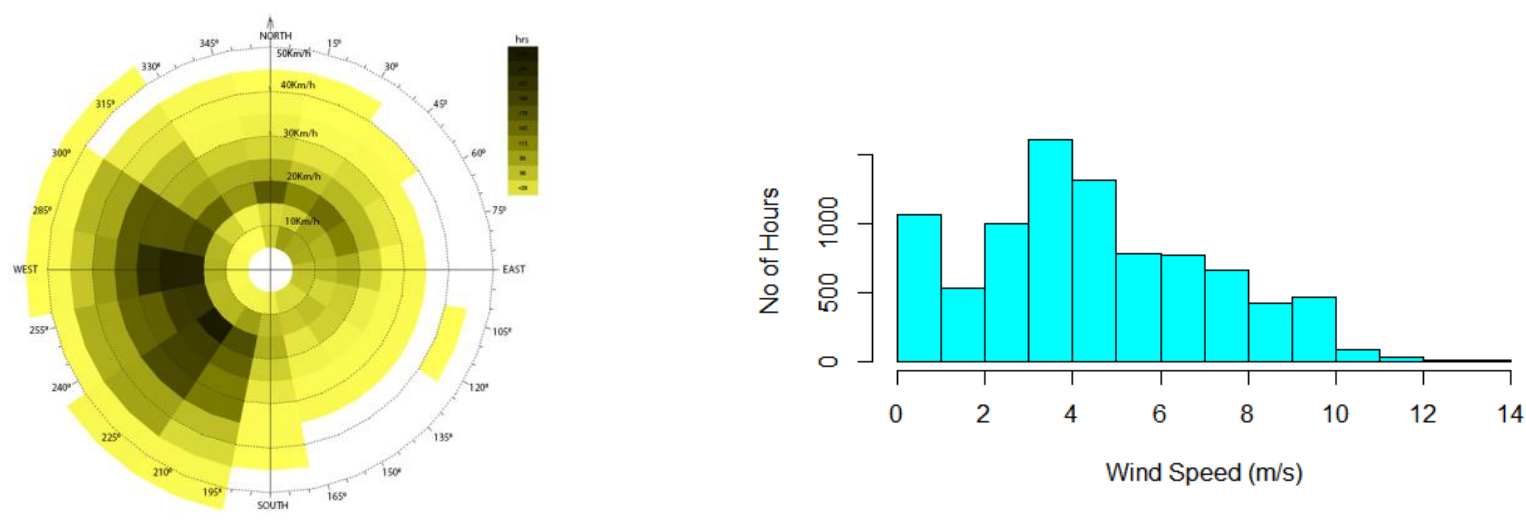

Figure 1:Year round wind Direction and velocity variations of Thiruvananthapuram 
of uniform surface cover, structure, material and human activity that spans from hundreds of meters to several kilometres in horizontal scale" and are classified in 17 classes with 10 classes built type and 7 natural types of land cover category. LCZ-2 is characterised by the properties listed in Table 1.

Table 1:Properties of LCZ-2
\begin{tabular}{|l|l|}
\hline PROPERTIES & \\
\hline Sky View Factor & $0.3-0.6$ \\
\hline Canyon aspect ratio & $0.75-2$ \\
\hline Mean building Height & $10-25 \mathrm{~m}$ \\
\hline Terrain Roughness class & $6-7$ \\
\hline Building surface fraction & $40-70 \%$ \\
\hline Impervious surface fraction & $30-50 \%$ \\
\hline Pervious Surface Fraction & $<20 \%$ \\
\hline Surface Albedo & $0.10-0.20$ \\
\hline Anthropogenic heat flux & $<75 \mathrm{Wm}^{-2}$ \\
\hline
\end{tabular}

\section{Experimental Design}

Keeping every properties of LCZ-2 within the prescribed limits, a parametric analysis of urban morphological variable is carried out using Response Surface Method (RSM) to examine their impact on ventilation availability. Fifteen combinations of urban morphology, represented by $\mathrm{L} / \mathrm{H}$ ratio (ranging from 0.5 to 2 ), $\mathrm{H} / \mathrm{W}$ ratio (ranging from 0.5 to 2 ) and wind incidence angle $\left(0^{0}\right.$ to $\left.90^{\circ}\right)$ were considered for the study (Fig 3,4). Each of the combination is simulated for minimum, average and maximum wind velocities $(0.1 \mathrm{~m} / \mathrm{s}, 4.5 \mathrm{~m} / \mathrm{s}$ and $14 \mathrm{~m} / \mathrm{s}$ ) which makes a total of 45 simulation cases.

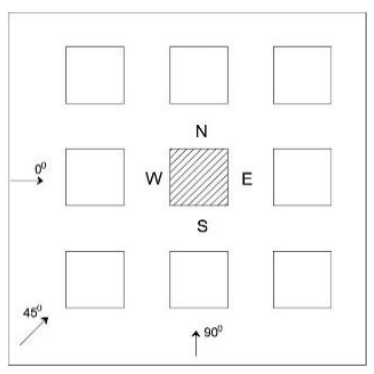

Figure 3:Schematic urban layout considered, with orientations and wind incidence angles

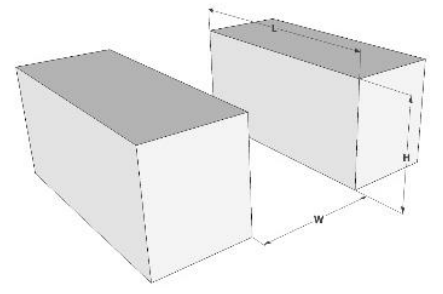

Figure 4:L-Length, H-height and W-gap between the buildings

CFD analysis was carried out for all the 45 combinations with the help of CFD tool Cradle SC-Stream- a commercial code for flow analysis. Flow analysis using standard k-eps turbulence model is carried out for a DayMarch 20 of typical year at $3 \mathrm{pm}$. The data was generated at $1.5 \mathrm{~m} \mathrm{X} 1.5 \mathrm{~m}$ grid interval. The ventilation availability of each combination was observed on all the four orientations at heights $1.8 \mathrm{~m}, 13 \mathrm{~m}$ and $21 \mathrm{~m}$ from the ground level ( height of the building being $25 \mathrm{~m}$ it constitutes low, middle and top level respectively).

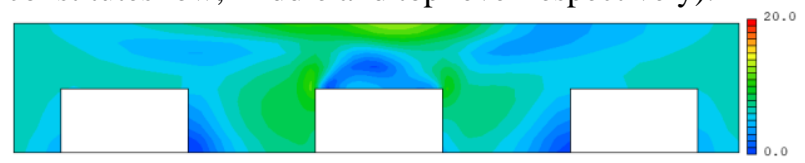

Figure 5:Ventilation Availability when $H / W-O .5, L / H-2$

Ventilation availability is maximum when the $\mathrm{H} / \mathrm{W}$ ratio is kept minimum and $\mathrm{L} / \mathrm{H}$ ratio was maximum. Whereas, when $\mathrm{H} / \mathrm{W}$ is increased and $\mathrm{L} / \mathrm{H}$ decreased, the ventilation availability also decreased as shown in Fig.5 and Fig.6. Similar scenario is observed when the input wind speed is varied between $0.1 \mathrm{~m} / \mathrm{s}, 4.5 \mathrm{~m} / \mathrm{s}$ and $14 \mathrm{~m} / \mathrm{s}$. at $1.8 \mathrm{~m}, 13 \mathrm{~m}$ level and $21 \mathrm{~m}$ level.

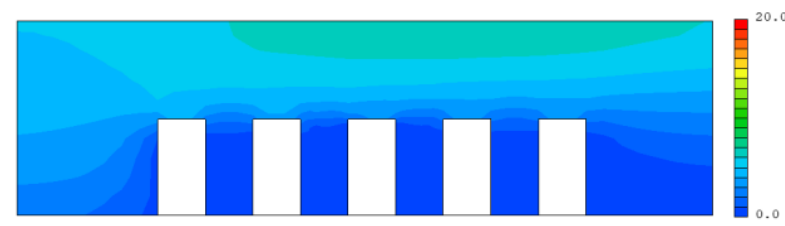

Figure 6:Ventilation Availability when $H / W-2, L / H-0.5$

Surface properties were kept constant for all the simulation runs. Due to the turbulence created by convection, at lower levels when solar exposure increases, wind speed increased. This will require further study which shall be reported later. Among the 15 combinations analysed, the combination with $\mathrm{H} / \mathrm{W}$ ratio $0.5, \mathrm{~L} / \mathrm{H}$ ratio 2 and wind incidence angle $45^{\circ}$, had the maximum ventilation availability and the combination with $\mathrm{H} / \mathrm{W}$ ratio $2, \mathrm{~L} / \mathrm{H}$ ratio 0.5 and wind incidence angle $90^{\circ}$ had the minimum ventilation availability. Thermal performance and comfort assessment were carried out for these two critical scenarios and compared with that of standard weather data.

\section{Result and Discussions}

Impact of Urban morphology on ventilation availability

Statistical analysis is conducted to find the relative impact of $\mathrm{L} / \mathrm{H}$ ratio, $\mathrm{H} / \mathrm{W}$ ratio and wind incidence angle on ventilation availability at north, east, south and west side of the chosen building.

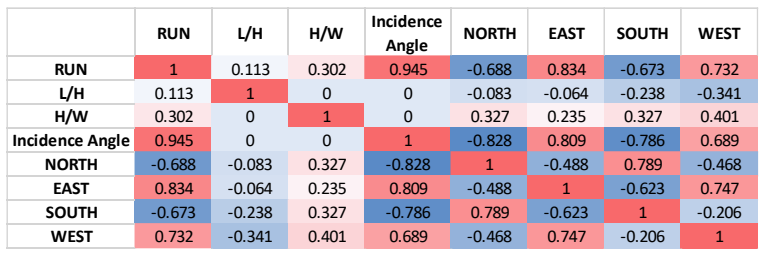

Figure 7:correlation matrix of urban morphological variables and Ventilation Availability at different orientations

It was observed that $\mathrm{L} / \mathrm{H}$ ratio has negative correlation with wind velocity at all the sides, i.e, as the $\mathrm{L} / \mathrm{H}$ increases ventilation availability decreases, whereas the ventilation availability increases with the increase of $\mathrm{H} / \mathrm{W}$ ratio. In the analysis, wind incidence from west $\left(0^{0}\right)$ to south $\left(90^{\circ}\right)$ was only considered as wind behaviour will be similar in other quadrants as well. It was observed that in north and 
south side as the wind incidence angle increase from $0^{0}$ to $90^{\circ}$ the ventilation availability decreases and in east and west side as the wind velocity incidence angle increase from $0^{0}$ to $90^{0}$, the ventilation availability also increases as described in Fig.7.

Table 2: Results of Statistical Analysis $(A=L / H$, $B=H / W, C=$ Wind Incidence Angle)

\begin{tabular}{|l|l|l|}
\hline Side & Regression Model & $\mathrm{R}^{2}$ \\
\hline NORTH & $\begin{array}{l}1.46+0.8079 * \mathrm{~B}-2.05 * \mathrm{C}- \\
0.6425 * \mathrm{BC}+1.27 * \mathrm{C}^{2}\end{array}$ & 0.92 \\
\hline EAST & $2.35+2.08 * \mathrm{C}$ & 0.71 \\
\hline SOUTH & $3.21+0.889 * \mathrm{~B}-2.14 * \mathrm{C}$ & 0.72 \\
\hline WEST & $3.39-0.8384 * \mathrm{~A}+0.985 * \mathrm{~B}+1.69 * \mathrm{C}$ & 0.75 \\
\hline
\end{tabular}

similar. At $1.8 \mathrm{~m}$ height, only angle of incidence of wind had impact on ventilation availability; $\mathrm{H} / \mathrm{W}$ and $\mathrm{L} / \mathrm{H}$ did not show any significant impact. This is majorly due to the wind blocking. Fig. 8 details the impact of $\mathrm{H} / \mathrm{W}$ ratio on ventilation Availability at each side. In Eastern Side $\mathrm{H} / \mathrm{W}$ ratio does not have a significant impact on ventilation availability.

\section{Wind incidence angle}

In northern side the quadratic model shows that incidence angle has significant impact $(\mathrm{p}=<0.0001)$, When the incidence angle is $90^{\circ}$, it receives the minimum wind velocity and at $0^{0}$ it receives the maximum wind velocity.

In eastern side, the data found to be best fitting in linear model. The ANOVA score for the model shows that
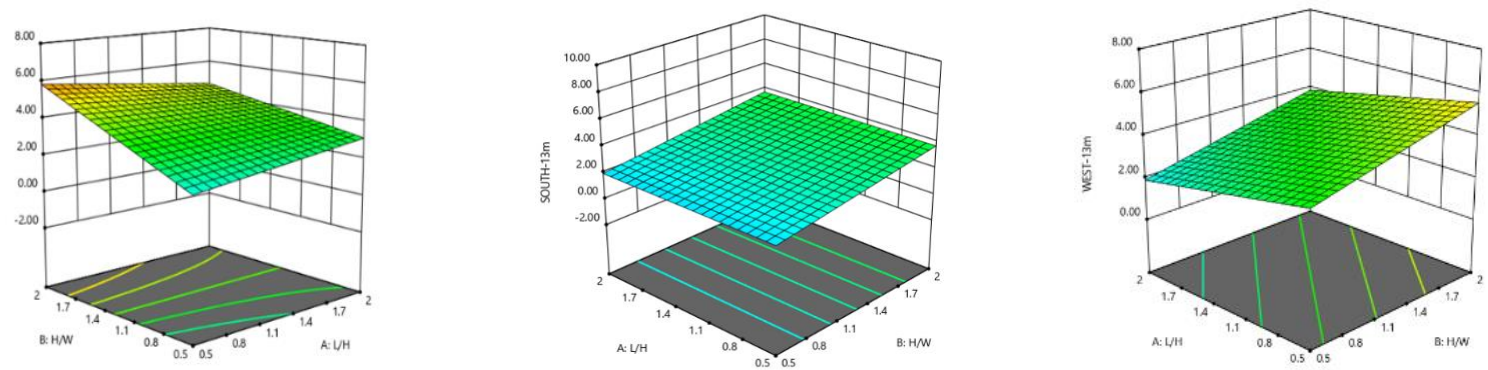

Figure 8: Ventilation Availability and $\mathrm{H} / \mathrm{W}$ ratio relation observed on North, West and South side at $13 \mathrm{~m}$ height

\section{H/W ratio}

At a height of $13 \mathrm{~m}$ from ground level at north side for an incident wind velocity of $4.5 \mathrm{~m} / \mathrm{s}$, it is found that quadratic model was more appropriate to fit the data $\left(\mathrm{R}^{2}=0.92\right)$. The model shows that $\mathrm{H} / \mathrm{W}$ ratio has considerable impact $(\mathrm{p}=0.0023)$ on ventilation availability. The $\mathrm{H} / \mathrm{W}$ ratio shows positive correlation with the wind. In the eastern side, the model shows that $\mathrm{H} / \mathrm{W}$ ratio is least contributing factor on ventilation availability. In southern side, $\mathrm{H} / \mathrm{W}$ ratio shows positive correlation $(\mathrm{p}=0.052)$ with ventilation availability for 4.5 $\mathrm{m} / \mathrm{s}$ input wind velocity. The study showed similar results when $0.1 \mathrm{~m} / \mathrm{s}$ and $14 \mathrm{~m} / \mathrm{s}$ were given as input wind velocities. Similar characteristics where observed when the same analysis was conducted at $21 \mathrm{~m}$ height from the ground level.

In western side, as the $\mathrm{H} / \mathrm{W}$ ratio increases the wind velocity also increases. At $13 \mathrm{~m}$ and $21 \mathrm{~m}$ height, for $0.1 \mathrm{~m} / \mathrm{s}, 4.5 \mathrm{~m} / \mathrm{s}$ and $14 \mathrm{~m} / \mathrm{s}$ input wind velocities, the impact on ventilation availability was found to be
$\mathrm{H} / \mathrm{W}$ and $\mathrm{L} / \mathrm{H}$ ratio are least contributing factors and the angle of wind incidence have significant impact $(p=0.0003)$ on the ventilation availability. It is observed that when angle of incidence was $0^{0}$ (west side), it received the minimum wind velocity and it increases as the angle increases towards $90^{\circ}$ (south). The analysis showed similar results for input wind velocities $0.1 \mathrm{~m} / \mathrm{s}, 4.5 \mathrm{~m} / \mathrm{s}$ and $14 \mathrm{~m} / \mathrm{s}$ at $1.8 \mathrm{~m}, 13 \mathrm{~m}$ and $21 \mathrm{~m}$ heights.

In southern side, the results reflect that incidence angle has significant impact $(p=0.0002)$ on the ventilation availability. When the incidence angle is $0^{0}$ (west) it receives the max wind velocity and at $90^{\circ}$ (south) it receives the least wind velocity. In western side the wind velocity also gets increased as the angle of incidence changes from $0^{\circ}$ (west) to $90^{\circ}$ (south). As it reduces the wind blocking caused by neighbouring blocks. Fig.9 explains the relationship on wind incidence angle on ventilation Availability. It also shows the contribution of $\mathrm{L} / \mathrm{H}$ on ventilation Availability on each side.
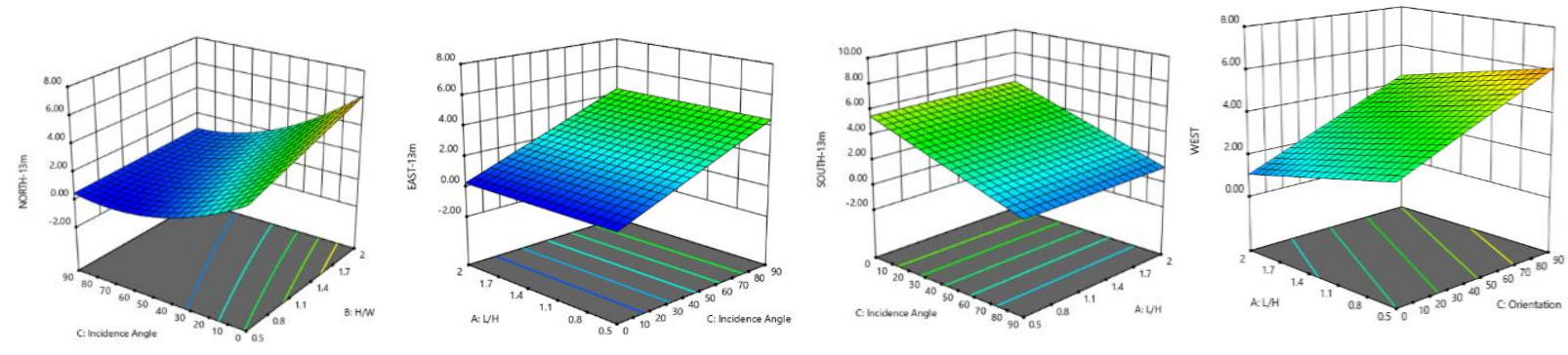


\section{L/H ratio}

$\mathrm{L} / \mathrm{H}$ ratio has least impact on ventilation availability in the northern side $(\mathrm{p}=0.358)$ at $13 \mathrm{~m}$ height and $21 \mathrm{~m}$ height Fig.10, whereas at $1.8 \mathrm{~m}$ height from the ground level, it was observed that $\mathrm{L} / \mathrm{H}$ ratio also influences the ventilation availability. This is due to the turbulance created by convection. This needs to be further studied by changing surface properties.

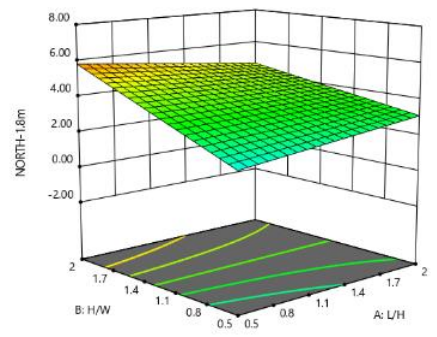

Figure 10: Ventilation Availability and $\mathrm{L} / \mathrm{H}$ ratio relation at $1.8 m$ height north side

In eastern side, the results indicate $\mathrm{L} / \mathrm{H}$ ratio to be the least contributing factor. $\mathrm{L} / \mathrm{H}$ ratio has least significance at southern side as well for input wind velocities of $0.1 \mathrm{~m} / \mathrm{s}, 4.5 \mathrm{~m} / \mathrm{s}$ and $14 \mathrm{~m} / \mathrm{s}$ at $1.8 \mathrm{~m}$ and $13 \mathrm{~m}$, whereas at $21 \mathrm{~m}$ level it was seen that $\mathrm{L} / \mathrm{H}$ ratio is negatively correlated to the wind velocity.

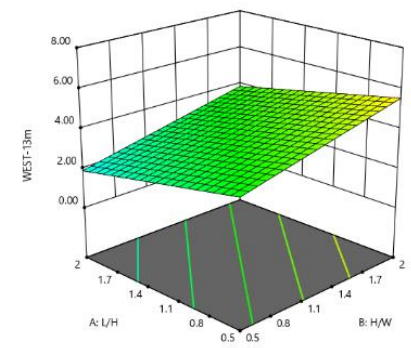

Figure 11:Ventilation Availability and $L / H$ ratio relation at $13 \mathrm{~m}$ height west side

In western side it was observed that the $\mathrm{L} / \mathrm{H}$ and ventilation Availability are negatively correlated due to the wind blocking as shown in Fig 11.

Impact of ventilation availability on thermal and comfort performance

A three-bedroom residential building predominantly operating in a free-running mode is considered for thermal performance and comfort study. The assessment is carried out using the Energy Plus for a single dayMarch 20 of a typical year. The study considers two different scenarios - (1) An assessment carried out using standard weather data of the city and (2) An assessment carried out using the micro-climate data (data with least and maximum ventilation availability). Among the 15 combinations analysed, the combination with $\mathrm{H} / \mathrm{W}$ ratio $0.5, \mathrm{~L} / \mathrm{H}$ ratio 2 and wind incidence angle $45^{0}$, has the maximum Ventilation Availability (referred as CASE-1) and the combination with $\mathrm{H} / \mathrm{W}$ ratio $2, \mathrm{~L} / \mathrm{H}$ ratio 0.5 and wind incidence angle $90^{\circ}$ has the minimum ventilation availability (referred as CASE-2).

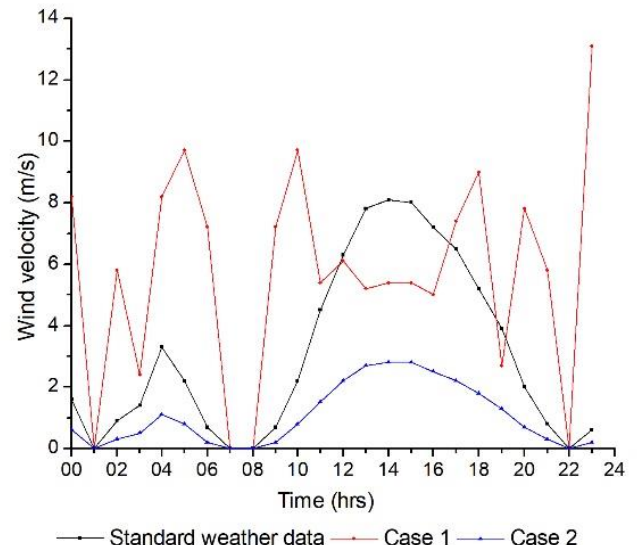

Figure 12: Variations in ventilation availability between standard weather data and microclimate data

The wind data of the standard weather file were replaced with that of these two critical scenarios for thermal performance and comfort assessment. Fig. 12 shows the difference in hourly ventilation availability on March-20 among standard weather data, CASE-1 and CASE-2.

Thermal performance analysis results points towards the variation in the results between the two cases. Results obtained from standard epw weather data were found to be between the two extreme micro climatic condition cases. Inaccuracies in weather data can thus lead to errors in thermal gain calculations through the building envelope as shown in Fig. 13.

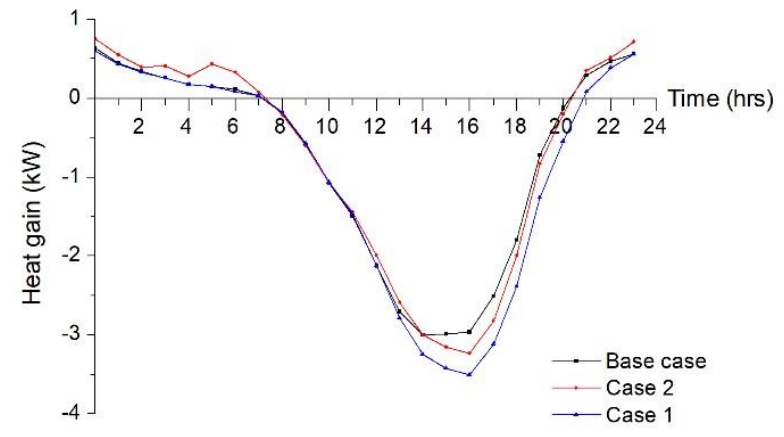

Figure 13: Variation in heat gain through envelop when standard weather data and microclimate data are used

Air changes per hour by ventilation and infiltration are found to be affected by the ventilation potential as shown in Fig.14. Cumulatively CASE-1 gives more ventilation $\mathrm{ac} / \mathrm{h}$ and shows more variation from the base case (covariance $=2.97$ ) owing to the large differences in the wind velocities. Lesser variation is observed between CASE-2 and the epw data (covariance=2.74) suggesting that epw weather data are more representative of weather with low wind speeds for the duration of analysis. 


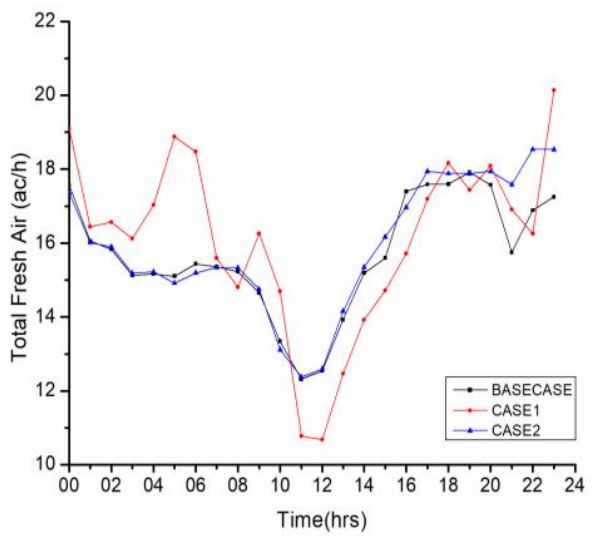

Figure 14:Variation in Total fresh air exchange when standard weather data and microclimate data are used

The thermal comfort assessment is carried out on the basis of PMV and TSI (Tropical Summer Index).

$$
T S I=0.308 t_{w}+0.745 t_{g}-2.06 \sqrt{V+0.841}
$$

$\mathrm{t}_{\mathrm{w}}=$ wet bulb temperature in ${ }^{0} \mathrm{C}$

$\mathrm{t}_{\mathrm{g}}=$ globe temperature in ${ }^{0} \mathrm{C}$

$\mathrm{V}=$ air speed in $\mathrm{m} / \mathrm{s}$.

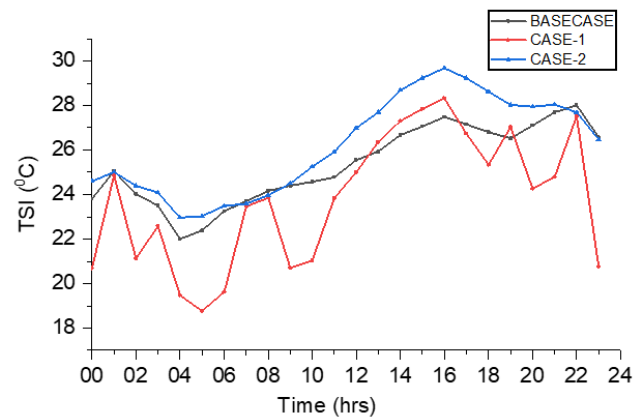

Figure 15: Variation in comfort performance when standard weather data and microclimate data are used

The TSI values for CASE 1 were lower than the Base Case and CASE 2 for most of the time, showing a higher value of TSI and corresponding high comfort scenarios for case 1 with higher values of wind velocity as shown in Fig. 15.

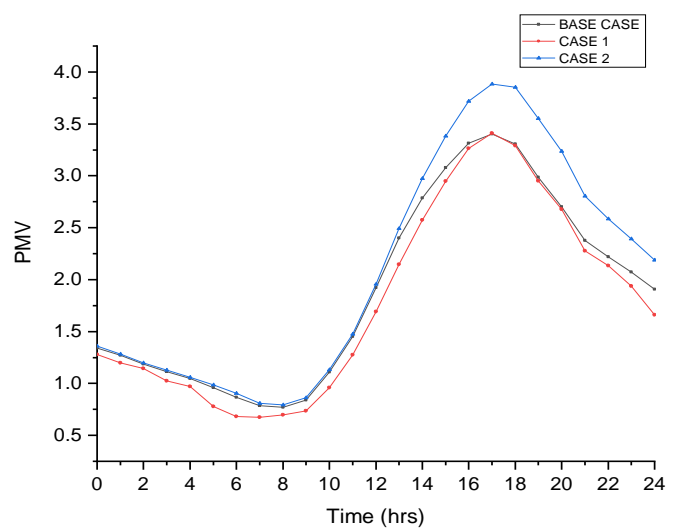

Figure 16: Variation in PMV when standard weather data and microclimate data are used
Thermal comfort analysis conducted based on PMV comfort index also showed similar results as shown in Fig.16. In CASE 1, when the ventilation availability was maximum the comfort level of the occupants inside was maximum and in CASE-2 when the ventilation availability was minimum the comfort level also decreased. With the temperature level being constant and the ventilation availability increased, the comfort level of the occupants inside increases.

Comparative study of both the cases shows that there is considerable variation in comfort and thermal performance when microclimatic data were used for simulation in place of standard epw weather data.

\section{Conclusion}

This study reveals the impact of different urban morphological variables on building microclimate. Among the variables assessed, $\mathrm{H} / \mathrm{W}$ ratio has maximum impact on increasing the ventilation availability, followed by the wind incidence angle, when a neighbourhood of LCZ-2 is considered. The increase in ventilation availability resulted in improved thermal and comfort performance. Accurate micro-climate data can reduce building performance prediction errors and can act as an important variable for model calibration during the stages of building design and calibration.

Results from the analysis highlights the variation in building performance characteristics when the impact of micro-climate variables are considered in analysis. Micro- climate data if used for building simulation, can provide more reliable energy predictions. Architects, designers and engineers can be greatly benefitted by this approach as more reliable assessment of building performance can be achieved. Future studies can further explore the impact of surface properties and solar radiation on building thermal and comfort performance.

\section{Reference}

Abd Razak, A., Hagishima, A., Ikegaya, N., \& Tanimoto, J. (2013). Analysis of airflow over building arrays for assessment of urban wind environment. Building and Environment, 59, 5665. https://doi.org/10.1016/j.buildenv.2012.08.007

Aflaki, A., Mahyuddin, N., Al-Cheikh Mahmoud, Z., \& Baharum, M. R. (2015). A review on natural ventilation applications through building façade components and ventilation openings in tropical climates. Energy and Buildings, 101, 153-162. https://doi.org/10.1016/j.enbuild.2015.04.033

Dimoudi, A., Kantzioura, A., Zoras, S., Pallas, C., \& Kosmopoulos, P. (2013). Investigation of urban microclimate parameters in an urban center. Energy and Buildings, 64, 1-9. https://doi.org/10.1016/j.enbuild.2013.04.014

Etheridge, D. (2015). A perspective on fifty years of natural ventilation research. Building and Environment, 91, 51-60. https://doi.org/10.1016/j.buildenv.2015.02.033 
Georgakis, C., \& Santamouris, M. (2006). Experimental investigation of air flow and temperature distribution in deep urban canyons for natural ventilation purposes. Energy and Buildings, 38(4), 367-376. https://doi.org/10.1016/j.enbuild.2005.07.009

Geros, V., Santamouris, M., Tsangrasoulis, A., \& Guarracino, G. (1999). Experimental evaluation of night ventilation phenomena. Energy and Buildings, 29(2), 141-154. https://doi.org/10.1016/S0378-7788(98)00056-5

Hughes, B. R., Chaudhry, H. N., \& Ghani, S. A. (2011). A review of sustainable cooling technologies in buildings. Renewable and Sustainable Energy Reviews, 15(6), 3112-3120. https://doi.org/10.1016/j.rser.2011.03.032

Oke, T. R. (1976). The distinction between canopy and boundary-layer urban heat islands. Atmosphere, 14(4), 268-277. Retrieved from https://doi.org/10.1080/00046973.1976.9648422

Oropeza-Perez, I., \& Ostergaard, P. A. (2014). Energy saving potential of utilizing natural ventilation under warm conditions - A case study of Mexico. Applied Energy, 130, 20-32. https://doi.org/10.1016/j.apenergy.2014.05.035

Oropeza-Perez, I., \& Østergaard, P. A. (2014). Potential of natural ventilation in temperate countries - A case study of Denmark. Applied Energy, 114, 520530. https://doi.org/10.1016/j.apenergy.2013.10.008

Pisello, A., Pignatta, G., Castaldo, V., \& Cotana, F. (2015). The Impact of Local Microclimate Boundary Conditions on Building Energy Performance. Sustainability, 7(7), 9207-9230. https://doi.org/10.3390/su7079207

Santamouris, M., Papanikolaou, N., Livada, I., Koronakis, I., Georgakis, C., Argiriou, A., \& Assimakopoulos, D. N. (2001). ON THE IMPACT OF URBAN CLIMATE ON THE ENERGY CONSUMPTION OF BUILDINGS, 70(3), 201216.

Simonson, C. (2005). Energy consumption and ventilation performance of a naturally ventilated ecological house in a cold climate. Energy and Buildings, 37(1), 23-35. https://doi.org/10.1016/j.enbuild.2004.04.006

Stewart, I. D., \& Oke, T. R. (2012). Local climate zones for urban temperature studies. Bulletin of the American Meteorological Society, 93(12), 18791900. https://doi.org/10.1175/BAMS-D-1100019.1

Vallati, A., De Lieto Vollaro, A., Golasi, I., Barchiesi, E., \& Caranese, C. (2015). On the impact of urban micro climate on the energy consumption of buildings. In Energy Procedia (Vol. 82, pp. 506511). https://doi.org/10.1016/j.egypro.2015.11.862 